\title{
Off the Wheel
}

\author{
Ajahn Amaro ${ }^{1}$ \\ Accepted: 6 March 2021 / Published online: 25 March 2021 \\ (C) Amaravati Publications 2021
}

When we talk about rebirth, people often think in terms of past lives, future lives - in what you could call a metaphysical way, beyond the scope of our everyday vision and perceptions. That perspective is understandable, and yet when the term "rebirth" or "the cycle of birth and death" (called the bhavacakka in the Suttas) is referred to, it is not always referring to a sequence of events over a number of lifetimes.

The Buddha does indeed refer matter-of-factly to our past lives and future lives in many instances throughout the teachings. That's a very common way of speaking.

But when talking about the process of rebirth, what causes it and how it is brought to an end, particularly the teachings on what is called dependent origination (paticcasamuppāda), the Buddha is often referring to more of a moment-to-moment experience. The Commentaries tend to focus more on dependent origination as a process which takes place over the course of several lifetimes, but careful study has shown that in the Suttas themselves, a full two-thirds of the Buddha's teachings on the subject refer to it as a momentary experience, a process that is witnessed in the here and now, in this very lifetime.

In Thailand last century, there was a very prominent writer, thinker, and teacher named Ajahn Buddhadasa. He emphasized that the way to make the teaching on dependent origination really useful is to understand it and apply it to our everyday life, our moment-by-moment experience. The Buddha's teaching is essentially practical, so pointing to the use of this teaching here and now, discovering how it can help us here in this very lifetime, is much more pertinent than talking about its relevance in past lives or future lives. Ajahn Buddhadasa confined his teachings of dependent origination to how it describes the arising of $d u k k h a$ here and now, how it comes into being in our present experience.

Ajahn Amaro

ajahn.amaro@gmail.com

1 Amaravati Buddhist Monastery, Great Gaddesden, Hemel Hempstead, Hertfordshire HP1 3BZ, UK
Ajahn Chah shared Ajahn Buddhadasa's understanding of dependent origination. He often talked about how it relates to our experience of the senses and how it gives rise to feelings of alienation, dissatisfaction, and discontent. In one of his most well-known analogies, he said that trying to keep track of the process of dependent origination, which is usually described as a sequence of 12 different segments, is like falling out of a tree and trying to count the branches on the way down - it all happens too quickly to allow you to keep track of all the 12 links, but you know that when you hit the ground, it hurts! He was a very practical teacher, and I think that graphic image is a helpful way of describing the process.

At the beginning of the Mahā-nidāna Sutta, a discourse on causality, Venerable Ānanda says to the Buddha, "I understand that dependent origination is really important and I have fully grasped it now. It is clear as clear can be to me." As the Buddha usually does in these instances he says, "Not so, Ānanda. You shouldn't say that dependent origination is "clear as clear can be" to you; it is subtle, deep, abstruse. This is not something easily understood. You're an intelligent person, Ānanda, but don't say you understand it. Don't be too glib about it. There are many layers and subtleties within it that you do not yet understand."

In brief, dependent origination describes how a lack of mindfulness, a lack of awareness of experience, leads to dissatisfaction - the arising of dukkha. The first link of the whole sequence is avijjä: ignorance, not seeing clearly, nescience. This means that when we don't see clearly, that is the trigger, the catalyst for the entire process. The root cause of suffering is avijja, not seeing clearly. If there's vijjā, if there is knowing, and if there is awareness, then suffering does not arise - there might be pain, but dukkha, anguish, dissatisfaction will not be caused.

As soon as avijj $\bar{a}$ is there, this leads to the fundamental delusion of subject and object.

Avijjā paccayā sankhārā-ignorance conditions formations. Luang Por Sumedho used to summarize this very succinctly: "Ignorance complicates everything." Sankhārā means that which is compounded, that which is formed. When there is ignorance, when the mind doesn't see clearly, this creates 
the foundation for the subject/object division. The subject/ object division strengthens in the next stage of the sequence: sankhārā paccayā viññānam - formations condition consciousness. Consciousness in turn conditions näma-rūpa-body and mind. A very wonderful Sri Lankan monk, Bhikkhu Nyānananda, calls this "the nāma-rūpa/viññanna vortex." You can create a mental image of this: once there is ignorance, there is the seed for the subject/object duality (a "here" and a "there"), which is like a whirlpool that gets stronger and stronger until it conditions the world of the senses (salāyatana).

The salayyatana, the six senses, are conditioned by that separation between subject and object, the knowing and the known. The spinning energy of the vortex makes it seem that seeing, hearing, smelling, tasting, touching, and thinking are all personal. Once there is the substantial feeling of a subject "here" and an object "there", this gives rise to the impression that there is a "me" who is seeing, hearing, smelling, tasting, touching, and thinking. Attachment to the senses then strengthens that duality, and the vortex gains energy.

When something is seen, heard, smelled, tasted, touched, or thought about, when one of the sense organs contacts an object, that is what we call "sense contact" (phassa). Sense contact leads to feeling, vedana. When there is phassa, there is an effect from that sense contact, a raw feeling that is either pleasant, painful, or neutral. That feeling then conditions craving, tanh $\bar{a}$. A pleasant feeling coupled with ignorance conditions a desire for more. An unpleasant feeling coupled with ignorance conditions a desire to get rid of. A neutral feeling coupled with ignorance is taken as a subtle kind of pleasant feeling; thus the mind inclines toward desire, and craving rapidly escalates. If these conditions are not seen clearly, if ignorance persists, then craving conditions clinging (upādāna) and the clinging conditions becoming (bhava). As you reach bhava, what you can see is a rising wave of absorption. First of all there is, say, a pleasant feeling. The mind thinks, "Ooh, what's that?" and then "Oh, wow! I'd like one of those!"

Just so this isn't too theoretical, imagine you are queuing up to get food. You see how many slices of cake there are left. As you approach the front of the queue you are trying to be mindful and restrained, but you are thinking, "There are only three slices left and there are five people in front of me. Hmm...look at that person in front of me. Is he a cake kind of a person? He looks like he's probably on a diet. I hope he is. But maybe he's not..." The mind sees an object; then there's the craving and craving leads to clinging. You think, "I really deserve a piece of cake. I really need to have a piece of cake." And then that clinging conditions becoming: "I've gotta have it! I've gotta have it! If he takes that last piece of cake, I know there is that precept about not killing, but..." The mind becomes absorbed, and getting that cake becomes the only important thing in the world. Suddenly the whole universe has shrunk to tanhhā upādāna bhava-"craving, clinging, becoming." The world narrows to that desire object. "I've gotta have it! I've gotta! I've gotta!" Bhava is that quality of the mind which is committed to getting its desire object. Everything else has been put aside. It is the thrill of riding the wave. When you see that last person in the food queue pass by the cake and you realize, "Yes! He IS on a diet! I'm gonna get it!", bhava is that thrill of guaranteed getting, acquisition.

Researchers have rigged people up with little electrodes, galvanic skin response measurers, and then sent them shopping. The test is designed to indicate the moment of maximum excitement in the shopping experience. You might be surprised to discover that scientists do this kind of thing, but they do - they measure the process of desire and excitement. The peak of excitement is the moment when you know that you're going to get the desired object. It is the moment when you hand over the money or the credit card and the person behind the counter accepts it. At that moment you are guaranteed to get the object of your desire, but it hasn't reached you yet. That is the moment of maximum excitement-when you actually get the piece of cake and take a bite, from there on it's all downhill. The moment of getting is already the beginning of the disappointment.

A. A. Milne, the author of Winnie the Pooh and a great philosopher of our age, makes this same observation: "Well!" said Pooh, "What I like best..." and then he had to stop and think because although eating honey was a very good thing to do, there was a moment just before you began to eat it which was better than when you were but you didn't know what it was called." (That was written in 1928, so he probably hadn't yet come across a translation of bhava.)

Even before you've got the honey in your mouth, you've reached the height of excitement-this is bhava. This is becoming. And as the Buddha pointed out, living beings are committed to becoming, they relish becoming, they adhere to becoming. "Becoming" is the drug of choice. We love that feeling because at that point life is very, very simple. "I want it, I'm going to get it—yes!"

Now, you might be thinking, "This is all very coarse. I'm totally beyond that kind of thing. Cake and pots of honey?! Pah! How inferior. This kind of thing does not bother me in the slightest." But translate them into your own particular value system - are you fixated on whether or not your paper has been selected for publishing in a prestigious journal, or whether you've won a promotion? Are you compelled by any one of a dozen different ways in which we rank ourselves in the world? Everyone has their own particular desire objects, but in a way the specific object of desire is secondary to the actual process of desire and becoming. All of us will have particular things that we find compelling, where the mind picks that object up and gets deeply absorbed in it. You can fill in the blanks for yourself, if pots of honey don't have any kind of pull on you. Look into your own mind, your own memories. What things really 
have a pull? The achievements of your children? The publication of your books? The approval of your teacher - that feeling you get if the Ajahn smiles at you? Or it could be getting any kind of affirmation. It can be wholesome or unwholesome, but in that process of bhava, the mind becomes completely absorbed, though it hasn't quite got the object yet.

After bhava the next link in the chain of dependent origination is jāti, which is birth. This is the point of no return. Now you've purchased the item, now you've got it. Shortly after comes the bill. Having acquired the desired object, there is a price to pay. Suppose you wanted to vent your spleen and complain about someone or become angry with them, so you really let them have it. While you're letting them have it you feel great: "He really had it coming!" Then after the spleen has been vented on somebody, there's what follows-soka parideva dukkha domanassa upāyāsāa: sorrow, lamentation, pain, grief and despair.

Having got what we wanted, we then get the whole package that comes along with it. If it was something pleasant, we are faced with the desire for more. If you are particularly enthusiastic about wonderful food, once you've eaten it you'll find you are left with an empty plate, and you may think to yourself, "Oh! Where did that food go? I'd better go get seconds, because I was so excited about the first round that I missed it completely. I'd better go and get some more."

So we end up with the experience of soka parideva dukkha domanassa up $\bar{a} y \bar{a} s \bar{a}$ - sorrow, lamentation, pain, grief, and despair. There is that feeling of despondency-you got what you wanted but then it didn't really satisfy you, or it wore out, or it was so sweet at the beginning and then it turned into hard work. You thought it was going to be so great that you didn't realize you were going to get all this other not-so-nice stuff with it. As Marilyn Monroe once sang: "After you get what you want you don't want it anymore." Thus whatever shape it takes, whether it's subtle or coarse, that dukkha feeling can be described as sorrow, lamentation, pain, grief, and despair. Perhaps we don't use that kind of language in the ordinary everyday world, only in monasteries, but it's that feeling of disappointment, of desolation, of sadness, of incompleteness; that sense of barrenness in the heart, feeling lonely, unsatisfied, insecure; dukkha, in other words.

The classic rendition of Dependent Origination consists of 12 links, beginning with ignorance — each link conditions the next:

(1-2) Ignorance conditions subject/object formation

(2-3) Formations condition consciousness

(3-4) Consciousness conditions body and mind

(4-5) Body and mind condition the senses

(5-6) The senses condition contact

(6-7) Contact conditions feeling

(7-8) Feeling conditions craving

(8-9) Craving conditions clinging
(9-10) Clinging conditions becoming

(10-11) Becoming conditions birth

(11-12) Birth conditions sorrow, lamentation, pain, grief, and despair

The process is mapped out in this way, but as Ajahn Chah said, it is like dropping out of a tree - it can happen very, very fast. The mind is caught by a sense object. There is the thought, "Oh, that looks interesting." And suddenly you've eaten the slice of cake, in spite of the fact that you are supposed to be on a diet. You are disappointed in yourself and think, "Well, I'll have to start the diet tomorrow"-soka parideva dukkha domanassa upāyāsā. The whole thing can happen literally in a finger-snap. This is what Luang Por Chah was pointing out when he described it as like dropping out of a tree - those 12 branches whizz past in a blur and the first thing you're aware of is hitting the ground.

It is useful to map things out in this way, examining the process of disappointment, dissatisfaction, and alienation. It is useful to examine how it takes shape, and how this multi-part sequence describes it. By understanding the process of our own experience, we can come to understand how not to become caught, how not to create the causes of that $d u k k h a$, and how not to be wrapped up in that cycle.

As the process is contemplated, we can recognize that there are different elements to it. There are different ways of breaking free. This cycle is called bhavacakka, "the cycle of becoming" or "the wheel of rebirth." It is called a cycle because at its end, it leaves us feeling incomplete, lonely, or sad, and the way we deal with that kind of mopey unhappiness is by resuming the cycle as soon as the possibility of another gratification comes along.

When the wave recedes, we are left slightly frazzled and insecure. Now, the last time when we were really happy, when we really felt gratified, was when we were caught in that thrill of becoming. So when something pops into view that has the allure of satisfaction, we say to ourselves, "Oh, well, that last one didn't work, but maybe the next one..."; and we leap toward the next possibility, the next promise, the next desire object, the next thing which has that aura around it. We delude ourselves into thinking that the next big thing is going to be different- this thing is going to be special, this time it's really going to work! And around and around we go, chasing that next object and pursuing that next goal. The objects upon which we fixate like this are not necessarily coarse or unwholesome. They could be the next meditation retreat, or even the next meditation cushion - the one that's going to enable me to sit for hours without pain. "Pain-free zafus! Yes! I've heard there's something on the market, with magic herbs in...."

This is how the deluded mind works-irrespective of whether the object is wholesome, unwholesome, or neutral, this is exactly how it works. The mind is caught in these cycles 
of dependency, cycles of addiction. With his teaching, the Buddha is trying to help us free the heart from this addictive process; the main form of which is addiction to becoming. The bhavacakka, the cycle of becoming - that is our drug of choice to which we are all habituated, whether it is becoming based on a coarse sense-pleasure, or becoming born of noble aspirations or caring for our family. The objects can vary from those which are reasonably wholesome to those which are downright destructive, but the process works in exactly the same way irrespective of the object, and if we don't understand how it works, we are inevitably trapped in that endless cycle of addiction. The Buddha's teaching helps us to recognize that trap and to break free from it.

Interestingly enough, maybe the first exit point is at the point of dukkha itself. You've already arrived. You've woken up. You find yourself barefoot, surrounded by broken glass, thinking, "How did I get here? I' $m$ in the middle of this mess again. How did I get into this? What's happening here?" The Buddha said (A 6.63) that suffering, dukkha, ripens in two ways: it either ripens in further suffering, in which you just keep repeating the cycles over and over again, or you ask yourself some questions: "How did I end up here? How did this happen? I said I wasn't going to get caught in this again, but here I am again... what happened here? I know there must be a way to get out of this. I've been going round and round in this cycle for years now-there has to be an alternative."

There is a feeling, an intuition in the heart, that there must be another way. At some level you realize that freedom from addiction must be a possibility. And that very intuition is what the Buddha refers to as faith, saddha. This is how suffering can be a cause for the arising of faith that addiction and endless suffering can't be the only possibility. There has to be an alternative.

Even if you haven't figured out what the alternative is or how to find it, something in the heart is saying to you that there has to be a way to become free of this. So the suffering you experience is a cause for the arising of faith, and that faith is a cause for a sense of delight or gladness - a sense of a possibility, a potential that this addictive habit can be broken. This brings about a relaxation, a calming of the body- the body relaxes and the mind arrives at a quality of sukha, happiness or contentment.

Contentment becomes a basis for concentration. When the heart is content and at ease, it is natural for the mind to focus on the present moment. When there is sukha, it becomes a basis for samādhi. Samādhi is then a cause for the arising of insight. When the mind is able to settle, focus, and attend to the present moment, insight arises naturally. This is called "knowledge and vision of the way things are." We are able to attend to the present. We can see how things work. The knowledge and vision of the way things are leads to letting go, non-attachment. The heart sees that everything is impermanent, empty, and not self. Habits of attachment and identification are relinquished. That letting go leads to freedom and to full enlightenment, full liberation.

There is a particular Sutta in which the Buddha describes this causal chain (S 12.23); it is known as the Transcendent Dependent Arising or Proximate Cause. It starts off as usual with ignorance and goes through the whole sequence from ignorance to suffering (dukkha). But then dukkha leads to saddha, to faith, and the sutta veers off in a whole new direction. Rather than going round and round the cycle — dukkha leading to more ignorance and thus to the continuing of the rebirth process - it spins off at the point of $d u k k h a$ and leads to faith, and faith leads to delight, to contentment, to concentration, to insight, and to liberation. So in a way the quality of suffering itself, the quality of $d u k k h a$, is the most accessible of all exit points.

That is one point where we can hop off the cycle. Another commonly spoken of point where one can break the cycle is the link between feeling and craving, between vedan $\bar{a}$ and tanh $\bar{a}$. When most meditation teachers talk about dependent origination and how the whole process works, they describe this point as the weakest link. When the mind is able to focus on feeling, there is a capacity for substantial mindfulness. There can be a clear and unconfused mindfulness with regard to pleasant, painful, and neutral feelings. But it is only when the mind buys into those feelings, trying to get rid of a painful feeling, grasp hold of a pleasant feeling, or actively ignore a neutral feeling, that the confusion really kicks in and then come craving, clinging, and becoming.

But at the point of feeling, the train is still in the station, and it is not moving. At the point of vedana , you can still get off the train, go and buy a few snacks, look through the newsagent's wares and buy a paper. The train is still sitting there. No problem-you can get on the train, find your seat. But once tanha kicks in, the train has started moving. In theory you could still get off-if it's not moving too quickly. But then it picks up speed fairly rapidly. By the time you reach upādanna, the train is really moving. When you get to bhava, it is definitely in motion and pulling out of the station. If you get off at this stage, it's going to be really nasty. By the time you reach $j \bar{a} t i$, the train is at full speed and there's definitely no getting off.

The realm of feeling, then, is the easiest point at which to break the cycle; you can see there is a pleasant feeling, you can see there is a painful feeling, you can see there is a neutral feeling; but the heart is not snared by the feeling, not caught in it.

Speaking of trains, I once had a sabbatical year in India. As I prepared for the trip, I wondered to myself what would be a good meditation theme, a good focus for practice. I knew many people who had spent time travelling in India and knew that it can be very physically and emotionally demandingparticularly if you're attached to schedules. When Ajahn Sucitto went on a 6-month walking pilgrimage to all the 
Buddhist holy places in India, the great Chinese monk Master Hsüan Hua advised him, "When you go to practice in the place of the Buddha, do not find fault with anyone or anything." I took that piece of advice and decided that my spiritual program, my Dhamma practice for India, would be similarly not to find fault with anyone or anything. Along with that I thought a good simple theme while I was travelling would be to spend the year meditating on feeling, to make that my focus - just feeling, because it is very easy for feeling to condition craving, and to go off into wanting to get rid of things we dislike or wanting things to be different from the way they are. And so I thought I would just make that a year to reflect on feeling. I resolved, "Whenever feelings arise, I'll make it my effort just to notice the feeling and not get caught up in wanting more of it if it's a pleasant feeling, or wanting to get away from it if it's an unpleasant feeling."

That was an extraordinarily helpful practice. I wanted to keep it simple, so it was a very useful piece of advice. There you are on a station platform and you are told, "Terribly sorry, sir, your train is delayed by eighteen hours." Then you recognize it's the I've-been-waiting-six-hours-already-and-I'vejust-been-told-I-have-to-wait-another-eighteen feeling - it is that particular kind of feeling. But I wasn't letting my mind get caught up in all the shoulds and shouldn'ts.

Another interesting one is when you go to the train station in time for the eight o'clock train, and find it has left already; and when you ask how come, they tell you that your train was preponed. Then you experience the I-didn't-even-knowthat-"preponed"-was-a-word feeling. Incidentally, if you look the word up in the Oxford English Dictionary, it is specified as being "most frequent in Indian English."

Luang Por Sumedho has been talking about meditating on feeling in this way for years and years, but even though I had heard him do so dozens of times-hundreds of times, probably - I had never really taken the trouble to apply it. The mind is always drawn beyond the feeling, adding on to it all the shoulds and shouldn'ts, and chasing after how it ought to be-being caught up in the follow-up to a feeling. So this practice is all about working with the feeling that is actually present.

For example, perhaps you find yourself in a situation where somebody is very upset about something and is asking you to fix it. Your habitual reaction is to feel you should do something. But if instead you say to yourself, "This is the feeling of someone-is-really-upset-and-they're-asking-me-to-fix-itthat is what this is," in a strange and mysterious way, you enable yourself to attune more completely to what is actually present. Out of that attunement, what is appropriate and helpful for the situation can arise. If we are busy trying to figure things out or just reacting from memory and hoping to sort things out without reflecting, we don't notice that we're already caught up in the experience, we haven't noticed our conceptual proliferations, and therefore our response is skewed. As I say, this is an extremely helpful practice, and you can use it any time - when you're queuing for food, feeling the standing-in-the-queue-at-lunchtime-trying-not-tothink-about-that-last-piece-of-cake feeling; or reading a book and feeling the I-wonder-if-I'm-almost-at-the-end-of-thechapter feeling; or experiencing the how-on-earth-did-heknow-I-was-thinking-about-that? feeling.

We bring attention to the actuality of what is present, and taking the trouble to do that opens up to us a huge amount of space, psychological space that is always present and always available. Often, though, we are unaware of that spaciousness because we get drawn into trying to fix things - either trying to grab hold or take advantage of a pleasant situation or trying to fend off or get away from a difficult or painful situation. But if we simply bring our attention to what is here, what is present, then we are able to employ the qualities of mindfulness and wisdom.

Luang Por Dun was a very much beloved elder Thai monk who passed away a few years ago. He was known to be an arahant. When he was in his nineties and in hospital for the first time in his life, one of his disciples asked him if he still experienced anger. Luang Por Dun answered that the anger was there, but he didn't accept it. He gave this answer in a very matter-of-fact way. It was as if he was saying that anger was there, but there was no place for it to land. The delivery arrives, but he doesn't sign for it, so it's returned to sender.

Ajahn Chah was very critical of fortune telling and amulets, and all that side of popular Buddhism and folk belief in Thailand. He wouldn't give much time at all to things like palmistry and astrology or play along with them. One day this fellow who was a palm reader came to visit the monastery. $\mathrm{He}$ knew that Ajahn Chah was really against this kind of thing, but he was desperately trying to sneak a look at the lines on Ajahn Chah's hands. Eventually he couldn't resist any longer, and he went up to Ajahn Chah and said, "Luang Por, I know you're probably going to be very upset with me, or critical. I really admire you and respect you a lot, but I'm a palmist and I can't resist asking you - can I have a look at your hands, please? And you can send me away if you like but I had to ask. I've come all this way..." Ajahn Chah gave him a good working-over for a few minutes, telling him this was totally pointless and stupid, and wasn't going to end his suffering for him. But eventually Ajahn Chah showed him his hands and asked, "So what is going to happen to me? Am I going to find a nice wife? Maybe I'm going to win the lottery." The fellow looked at his hands and said, "Oh! Luang Por, you have to forgive me for saying this, but this line here says you have a lot of anger." Luang Por answered, "Yes, but I don't use it."

This is the way in which great beings completely end ignorance. The feeling of aversion and negativity can be there, but there's no place for it to land, there's nothing for it to hang on to. The feeling of aversion or anger arrives at the door, but there's nobody to sign for it. There's no place for it to land, so 
it does not give rise to any kind of unwholesome action or speech, or anything negative.

This is why the meditation upon feeling is a very helpful practice. Just try to stay in the realm of feeling and watch as feeling tries to drift toward craving. There's a big difference between liking and wanting, or not liking and hating. They're not the same things. We can hear something or feel something that we do not like; we can recognize that we do not like it - it is an ugly sound or a painful feeling - but we don't have to contend against it. We don't have to hate it. Liking or disliking can be completely peaceful. But as soon as they transmute into wanting or hating, there is a distortion. You can't be peaceful and hate at the same time. That doesn't work. But if there is an ache or a pain in the body, you can dislike it but still be at peace with it. There can be a clarity: "Ouch, I don't like that." But no contention arises against it, no hatred toward it. That is a prime opportunity and an important area of the practice to develop. See how that works. See if you can stay in the realm of feeling, because feeling is innocent. In feeling there is no intrinsic confusion or alienation. There can be a complete and comprehensive quality of clarity and peacefulness in relationship to feeling.

You can be at peace even with powerful painful emotions like grief or sadness or feelings of loss. Even the Buddha expressed that kind of sadness. There is a very poignant moment in one of the Suttas (S 47.14) when Venerables Sāriputta and Moggallāna (his two chief disciples) have passed away, and the Buddha looks round the assembly and says, "It's as if the assembly is empty now that Sāriputta and Moggallāna have gone. The assembly is empty now that these great beings have passed on." So even the Buddha could experience that sense of "My old friends have died. They've gone. They're not here any more." But he also knew how not to make a problem of it. There was no suffering within him on account of that.

The last exit point from the bhavacakka, which I'll just mention very briefly, is not to let the whole thing begin in the first place. As the mind is trying to drift into avijja $\overline{\text {, igno- }}$ rance, notice that. When mindfulness starts to slip, don't allow avijja to come into being. Don't let that dulling or obscuration arise.

This is something to practice when the mind is very clear and awake in meditation. You can see the mind being drawn toward a sound or a memory or a feeling - it is almost like a tugging at your body or your clothes. You can feel the mind being drawn into wanting to attach to this, wanting to have an opinion about that or to remember this, or to absorb into a like or a dislike. Don't let that happen. Don't let that complication arise. Just stay with the quality of $v i j j \bar{a}$-awakened awareness, knowing. Be that very knowing. Watch those urges. Be aware of the mind trying to lurch toward an opinion or a memory or a sound, lurching toward avijjā. And then, having seen that, calmly say "No" - do not allow that ignorance to arise. This is the most subtle but also the primary and most complete way of breaking the cycle - not to let the cycle arise in the first place.

Excerpted from The Breakthrough by Ajahn Amaro, Amaravati Publications, 2016.

Publisher's Note Springer Nature remains neutral with regard to jurisdictional claims in published maps and institutional affiliations. 